MATEC Web of Conferences 33, 03014 (2015)

DOI: $10.1051 /$ matec conf/ 20153303014

(C) Owned by the authors, published by EDP Sciences, 2015

\title{
Design, fabrication and characterization of porous Ti-rich Ti-Ni alloy based composites with near-zero thermal expansion behavior
}

\author{
Xiao Ma ${ }^{\mathrm{a}}$, Junping Luo, Shanshan Cao and Xinping Zhang \\ School of Materials Science and Engineering, South China University of Technology, Guangzhou 510640, Guangdong, China
}

\begin{abstract}
Porous Ti-rich Ti-Ni alloy based composites with near-zero thermal expansion (NZTE) behaviour tailored by micro-sized $\mathrm{SiC}$ particles were fabricated using powder metallurgy and a two-step designing strategy. At first, the $\mathrm{Ni}$ concentration was tuned to broaden the temperature range of negative thermal expansion (NTE) of porous Ti-Ni alloys; then micro-sized SiC particles of different amounts were introduced and co-sintered with mixed $\mathrm{Ti}$ and $\mathrm{Ni}$ powders having an optimized atomic ratio so as to obtain $\mathrm{SiC} / \mathrm{Ti}-\mathrm{Ni}$ composites with desirable thermal expansion performance. Results show that there is a clear correlation between the reverse martensitic transformation and NTE temperature range. The porous $12 \mathrm{wt} . \% \mathrm{SiC} / \mathrm{Ti}-43.8 \mathrm{at} . \% \mathrm{Ni}$ composite exhibits very low coefficient of thermal expansion (CTE) of $-0.976 \times 10^{-6} \mathrm{~K}^{-1}$ from 114.08 to 131.50 ${ }^{\circ} \mathrm{C}$. It is proposed that the NTE behavior originates from the volume change accompanying the phase transition of the Ti-Ni matrix, and the NZTE performance of $\mathrm{SiC} / \mathrm{Ti}$-Ni composites is attributed to the combination of the NTE produced by the alloy matrix and the positive thermal expansion provided by the $\mathrm{SiC}$ phase.
\end{abstract}

\section{Introduction}

The negative thermal expansion (NTE) materials are promising candidates for tuning the coefficient of thermal expansion (CTE) of the overall system. By compositing NTE materials with normal positive thermal expansion (PTE) materials, the desirable property of near-zero thermal expansion (NZTE) can be achieved [1], which is significant for the stability of materials and structures working under heat flow or thermal stress [2]. Thus far, the majority of studies on NTE and NZTE materials focused on inorganic non-metallic materials, such as $\mathrm{ZrW}_{2} \mathrm{O}_{8}$ [3], perovskites, antiperovskite [4] and their composites. Among the rarely explored candidates of metal alloys, Ni-Ti alloys of unique shape memory effect, super-elasticity, excellent mechanical properties and good biocompatibility [5] exhibit larger phase transformation induced negative CTE than non-metallic materials [6,7], and thus have drawn strong interests. Moreover, porous $\mathrm{Ni}-\mathrm{Ti}$ alloys allowing tunable CTE by compositing with PTE reinforcement have been reported to possess higher specific strength and lower density than the dense alloys [8], which enables the composites to be excellent candidate of metallic NZTE materials and offer promising applications in various areas. Materials with a low CTE or NTZT are required in various fields, for instance, in electronic packaging technology, because the thermal stresses generated by the thermal expansion in the electronic devices strongly affects the mechanical or electrical properties in the packaging. In this study,

\footnotetext{
${ }^{\mathrm{a}}$ Corresponding author: maxiao@scut.edu.cn
}

porous Ti-Ni based composites with NZTE effect tailored by $\mathrm{SiC}$ was successfully fabricated via powder metallurgy technique through a two-step strategy, in which a porous Ti-Ni alloy with optimized NTE temperature range was first achieved by tuning the $\mathrm{Ni} / \mathrm{Ti}$ atomic ratio, and then micro-sized $\mathrm{SiC}$ particles of PTE as reinforcement in $\mathrm{Ni}-\mathrm{Ti}$ alloy were introduced into $\mathrm{Ti}$ $\mathrm{Ni}$ alloy to obtain $\mathrm{SiC} / \mathrm{Ti}-\mathrm{Ni}$ composite with desirable NZTE performance. The mechanism of the NZTE behavior of the fabricated composites was also discussed.

\section{Experimental}

For the porous Ti-Ni alloys, Titanium and Nickel powders (50 and $61 \mu \mathrm{m}$ respectively, $99.9 \%$ purity) with a nominal atomic ratio of $100-x$ to $x(42<x<45)$ were blended for $24 \mathrm{~h}$ followed by cold compact in a hydraulic presser at $50 \mathrm{MPa}$. While for the Ti-Ni based composites, SiC powders $(50 \mu \mathrm{m}, 99.99 \%$ purity) of different weight fractions, $5 \%, 10 \%, 12 \%$ and $15 \%$, were blended with well-mixed powders of Titanium and Nickel at the optimized atomic ratio before compacting. The cylindershaped green samples $(16 \times 30$, diameter $\times$ height, $\mathrm{mm})$ were subjected to sintering at $1000{ }^{\circ} \mathrm{C}$ for $3 \mathrm{~h}$ under a protective atmosphere of flowing argon gas $(99.99 \%$ purity). Finally, all sintered samples were aged at $450{ }^{\circ} \mathrm{C}$ for $0.5 \mathrm{~h}$ followed by ice-water quenching.

Phase transformation temperatures of the as-prepared samples were characterized by a differential scanning 
calorimeter (DSC Q200, TA) at a heating/cooling rate of $10{ }^{\circ} \mathrm{C} / \mathrm{min}$. The thermal expansion strain of all samples with cylinder shape $(6 \times 25$, diameter $\times$ height, $\mathrm{mm})$ were measured by a thermo-mechanical analyzer (DIL 402C, $\mathrm{NETZSCH}$ ) at a heating rate of $10{ }^{\circ} \mathrm{C} / \mathrm{min}$ in the temperature range of 30 to $200{ }^{\circ} \mathrm{C}$. Also, the instantaneous coefficient of linear thermal $\alpha$ and its average $\alpha_{\text {average }}$ over certain temperature range for all samples were calculated based on the as-measured thermal strain. The $\alpha$ is defined as:

$$
\alpha=\left(1 / \mathrm{L}_{0}\right) /(\mathrm{dL} / \mathrm{dT})
$$

where $\mathrm{dL}$ and $\mathrm{dT}$ are the variations in length and temperature respectively, $\mathrm{L}_{0}$ is the initial length at room temperature, $\mathrm{dL} / \mathrm{L}_{0}$ is the thermal expansion strain.

A scanning electron microscopy (SEM, NanoSEM 430, FEI) and an X-ray diffractometer (XRD, Philips X pert MPD) were used to characterize the microstructure and constituent of the as-prepared $\mathrm{Ti}-\mathrm{Ni}$ based composites.

\section{Results and discussion}

To optimize the NTE behavior and understand its mechanism in the porous $\mathrm{Ti}-\mathrm{Ni}$ alloy, it is imperative to know first the phase transformation behavior in the alloy. The austenite start $\left(\mathrm{A}_{\mathrm{s}}\right)$ and finish $\left(\mathrm{A}_{\mathrm{f}}\right)$ temperatures detected by DSC in the alloys with Ni fraction varying from 42.5 to 44.7 at. $\%$ are shown in Table 1. The start and finish temperatures exhibiting NTE behaviour are designated as $T_{s}$ and $T_{f}$ respectively. The NTE temperature ranges $\left(\triangle \mathrm{T}_{\mathrm{NTE}}\right)$ with - ve $\alpha$ obtained by DIL and values of $\alpha_{\text {average }}$ over the corresponding NTE temperature ranges are also listed. It can be found that all porous Ti-Ni alloys undergo an expected austenite transformation and present NTE effect in the testing range of $30-200{ }^{\circ} \mathrm{C}$. Moreover, the austenite transformation temperature range $\left(\mathrm{A}_{\mathrm{f}}-\mathrm{A}_{\mathrm{s}}\right)$ have an obvious impact on $\Delta \mathrm{T}_{\mathrm{NTE}}$. According to Figure 1(a), both $\left(\mathrm{A}_{\mathrm{f}}-\mathrm{A}_{\mathrm{s}}\right)$ and $\triangle \mathrm{T}_{\mathrm{NTE}}$ show a parabolic-like tendency with increasing $\mathrm{Ni}$ fraction and reach the maximum at 43.8 at.\%, with a $\Delta \mathrm{T}_{\mathrm{NTE}}$ of $32.54^{\circ} \mathrm{C}$ and a corresponding $\alpha_{\text {average }}$ of $-7.83 \times 10^{-6} \mathrm{~K}^{-1}$. As is shown in Figure $1(\mathrm{~b})$, $\Delta \mathrm{T}_{\mathrm{NTE}}$ shows a linear dependence on and increases with $\left(\mathrm{A}_{\mathrm{f}}-\mathrm{A}_{\mathrm{s}}\right)$. This significant influence of austenite transformation behavior on the NTE temperature range can be understood as the fact that the unique NTE phenomenon of porous $\mathrm{Ti}-\mathrm{Ni}$ alloys is generally attributed to the martensitic and its inverse (austenite) transformations, which normally lead to an increase of the unit cell volume and consequently a net increase in the dimension of the alloy upon cooling and vice versa [9].

On the other hand, the influence of Ni fraction on the NTE can be understood as following. Defects at different dimensions (i.e., secondary particles, dislocations, point defects) introduced by different $\mathrm{Ni}$ fractions and discontinuous structure of porous $\mathrm{Ti}-\mathrm{Ni}$ alloys which contribute to the austenite transformation temperature range by hindering the transformation, will finally make an impact on the NTE temperature ranges. Further, it can be figured out from the data in Table 1 that NTE effect lags behind the austenite transformation rather than synchronous. This is understandable since the volume contraction of the unit cell needs to accumulate to be reflected by the $\alpha_{\text {average }}$ as a macro-scale parameter measured with samples in much larger size in DIL than that of austenite transformation temperatures in DSC. However, it is worth noting that the NTE effect of the materials cannot be simply counted as the accumulation of the unit cell volume change during transformation. It is a complicated process of the volume contraction propagation from atomic scale to macro-scale when considering the issues of defects, boundaries and orientation of martensite in Ti-Ni alloys. This also explains the fact that the $\alpha_{\text {average }}$ of porous Ti-Ni alloys in this study does not show regular variation corresponding to the Ni fraction according to Figure 1(a).

Table 1. Austenite transformation temperature range, NTE temperature interval and the corresponding $\alpha_{\text {average }}$ of porous Ti-Ni alloys with different $\mathrm{Ni}$ fractions.

\begin{tabular}{cccc}
\hline \multirow{2}{*}{ Ni(at.\%) } & \multicolumn{3}{c}{$\mathrm{B} 19^{\prime} \rightarrow \mathrm{B} 2$} \\
\cline { 2 - 4 } & $\mathrm{A}_{\mathrm{s}}\left({ }^{\circ} \mathrm{C}\right)$ & $\mathrm{A}_{\mathrm{f}}\left({ }^{\circ} \mathrm{C}\right)$ & $\mathrm{A}_{\mathrm{f}}-\mathrm{A}_{\mathrm{s}}\left({ }^{\circ} \mathrm{C}\right)$ \\
\hline 42.5 & 89.7 & 111.3 & 21.4 \\
43.0 & 85.6 & 110.4 & 24.8 \\
43.5 & 82.9 & 109.3 & 26.4 \\
43.8 & 81.7 & 108.3 & 26.6 \\
44.0 & 85.2 & 108.0 & 22.8 \\
44.7 & 80.3 & 100.4 & 20.1 \\
\hline
\end{tabular}

\begin{tabular}{|c|c|c|c|c|}
\hline \multirow{2}{*}{ Ni(at.\%) } & \multicolumn{3}{|c|}{ NTE } & \multirow{2}{*}{$\begin{array}{c}\alpha_{\text {average }} \\
\left(\times 10^{-6} \mathrm{~K}^{-1}\right)\end{array}$} \\
\hline & $\mathrm{T}_{\mathrm{s}}\left({ }^{\circ} \mathrm{C}\right)$ & $\mathrm{T}_{\mathrm{f}}\left({ }^{\circ} \mathrm{C}\right)$ & $\triangle \mathrm{T}_{\mathrm{NTE}}\left({ }^{\circ} \mathrm{C}\right)$ & \\
\hline 42.5 & 105.12 & 129.96 & 24.84 & -5.56 \\
\hline 43.0 & 114.64 & 143.76 & 29.12 & -8.94 \\
\hline 43.5 & 115.70 & 146.86 & 31.16 & -8.81 \\
\hline 43.8 & 111.57 & 144.11 & 32.54 & -7.83 \\
\hline 44.0 & 111.56 & 140.24 & 28.68 & -9.64 \\
\hline 44.7 & 115.54 & 138.18 & 22.64 & -8.71 \\
\hline
\end{tabular}



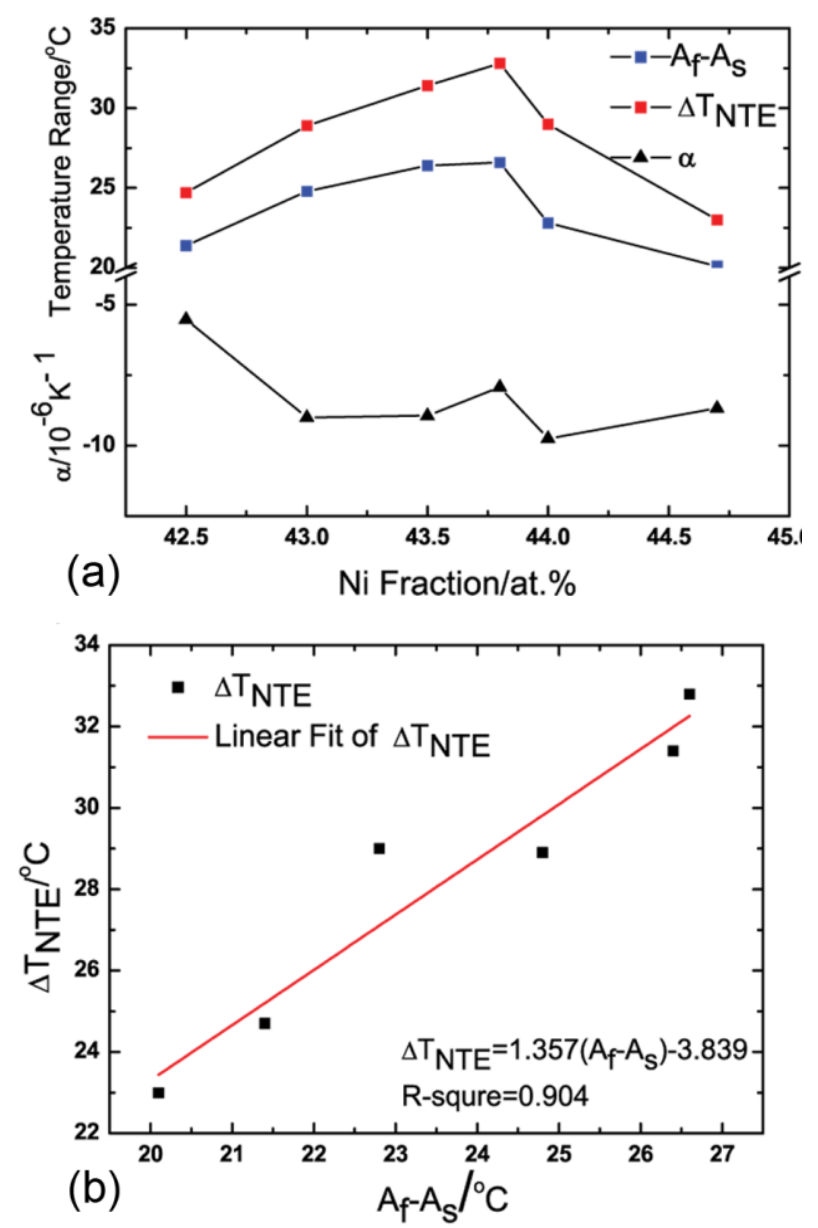

Figure 1. (a) Variation of austenite transformation range $\left(\mathrm{A}_{\mathrm{f}}-\mathrm{A}_{\mathrm{s}}\right), \mathrm{NTE}$ temperature interval $\left(\Delta \mathrm{T}_{\mathrm{NTE}}\right)$ and corresponding $\alpha_{\text {average }}$ of porous Ti-Ni alloys with different Ni fraction. (b) Relationship between $\Delta \mathrm{T}_{\mathrm{NTE}}$ and $\left(\mathrm{A}_{\mathrm{f}}-\mathrm{A}_{\mathrm{s}}\right)$ of porous Ti-Ni alloys.

Since the porous $\mathrm{Ti}-\mathrm{Ni}$ alloy with optimized $\mathrm{Ni} / \mathrm{Ti}$ atomic ratio and known coefficient of linear thermal expansion (CLTE) was successfully achieved, the Ti-Ni based NZTE composites can be designed based on the above results. In this study, $\mathrm{SiC}$ particles with weight fractions of $5 \%, 10 \%, 12 \%$ and $15 \%$ are composited with the porous $\mathrm{Ti}-43.8$ at. $\% \mathrm{Ni}$ alloy respectively. The thermal expansion strain curves in the testing range of 30 to 200 ${ }^{\circ} \mathrm{C}$ of the above composites and the porous $\mathrm{Ti}-43.8 \mathrm{at} . \% \mathrm{Ni}$ alloy are given in Figure 2 for comparison. It can be figured out that the expansion strain curves of both the composites and $\mathrm{Ti}-\mathrm{Ni}$ alloy show an obvious kink starting at around $110{ }^{\circ} \mathrm{C}$, which indicates the decrease or decelerating increase of the thermal expansion caused by the austenite transformation of the matrix of Ti-Ni alloy. On the other hand, the NTE effect of Ti-Ni alloy is efficiently suppressed by introducing $\mathrm{SiC}$ particles. By varying the $\mathrm{SiC}$ fraction from $5 \%$ to $15 \%$, the expansion strain and the CLTE of $\mathrm{SiC} / \mathrm{Ti}-\mathrm{Ni}$ composites in the "kinked" range is tuned from negative to positive. Among these composites, the $12 \mathrm{wt} . \% \mathrm{SiC} / \mathrm{Ti}-43.8 \mathrm{at} . \% \mathrm{Ni}$ one display the desirable NZTE property with an average CLTE of $-0.9787 \times 10^{-6} \mathrm{~K}^{-1}$ in the temperature range of 113.7 to $131.6^{\circ} \mathrm{C}$, which is comparable to Invar alloy [4].

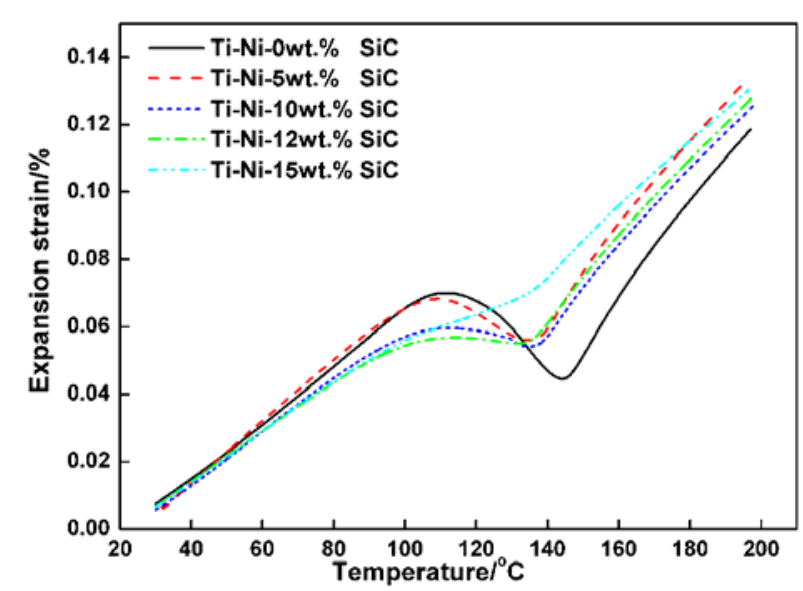

Figure 2. Thermal expansion strain curves of porous Ti43.8at.\%Ni alloy and $\mathrm{SiC} / \mathrm{Ti}-\mathrm{Ni}$ composites with the $\mathrm{SiC}$ fractions of $5 \%, 10 \%, 12 \%$ and $15 \%$.

The XRD pattern and SEM image of the porous $12 \mathrm{wt} . \% \mathrm{SiC} / \mathrm{Ti}-43.8$ at. $\% \mathrm{Ni}$ composite with optimized NZTE property are shown in Figure 3. Clearly, the composite mainly consists of $\mathrm{NiTi}\left(\mathrm{B} 19^{\prime}\right)$ and $\mathrm{Ti}_{2} \mathrm{Ni}$ as that in porous Ti-Ni alloys and minor SiC. A very small amount of chemical reactants between Ti-Ni matrix and SiC generating during sintering, which mainly include TiC and $\mathrm{Ni}_{2} \mathrm{Si}$ also present in the composite [8]. According to the SEM image, $\mathrm{SiC}$ embedded in the matrix of porous Ti-Ni alloy still retain the particle-like shape. Thus, it is clear that the thermal expansion behavior of the $\mathrm{SiC} / \mathrm{Ti}-\mathrm{Ni}$ composites is the comprehensive result of the simple mixture of $\mathrm{SiC}$ and Ti-Ni alloy. It should also be noted that multiple secondary phases, mainly $\mathrm{Ti}_{2} \mathrm{Ni}$, were formed during the sintering process of NiTi alloys. Bhagyaraj et al. [10] investigated the behavior and effect of $\mathrm{Ti}_{2} \mathrm{Ni}$ phase during processing of NiTi SMA and found that the amount of this secondary phase is about $1 \sim 2 \%$ by volume. Furthermore, $\mathrm{Ti}_{2} \mathrm{Ni}$ phase, as well as $\mathrm{SiC}$ particles, do not undergo phase transformation within the range of the testing temperatures. Therefore the negative thermal behavior is solely induced by the NiTi intermetallic matrix, and $\mathrm{Ti}_{2} \mathrm{Ni}$ second phase has, but very limited, contribution to the overall CTE due to the present small amount. Furthermore, it is also found that the thermodynamic driving force for the formation of $\mathrm{Ni}_{2} \mathrm{Si}$ and $\mathrm{TiC}$ in the present case can be high since the Gibbs free energies of $\mathrm{Ni}_{2} \mathrm{Si}(-142.7 \mathrm{~kJ} / \mathrm{mol})$ and $\mathrm{TiC}(-184.1$ $\mathrm{kJ} / \mathrm{mol})$ are much lower than that of $\mathrm{SiC}(-71.4 \mathrm{~kJ} / \mathrm{mol})$ at elevated temperatures, as well as the strong reactivity of pure $\mathrm{Ti}$. With the increasing amount of $\mathrm{SiC}$, the chemical interactions between the mixing components will become significant and the transformation characteristics of the composite will become complicated. A systematic study on the effect of the SiC content on the phase transformation behavior of the composite, and the underlying principle responsible for the impact, is needed. However, in our preliminary studies where only small amount of $\mathrm{SiC}$ was added (less than $10 \%$ ), it is found that 
the influence of the $\mathrm{SiC}$ on the thermal responses of the composite is minor in terms of the forward and reverse phase transformation temperatures, as shown in Figure 4.
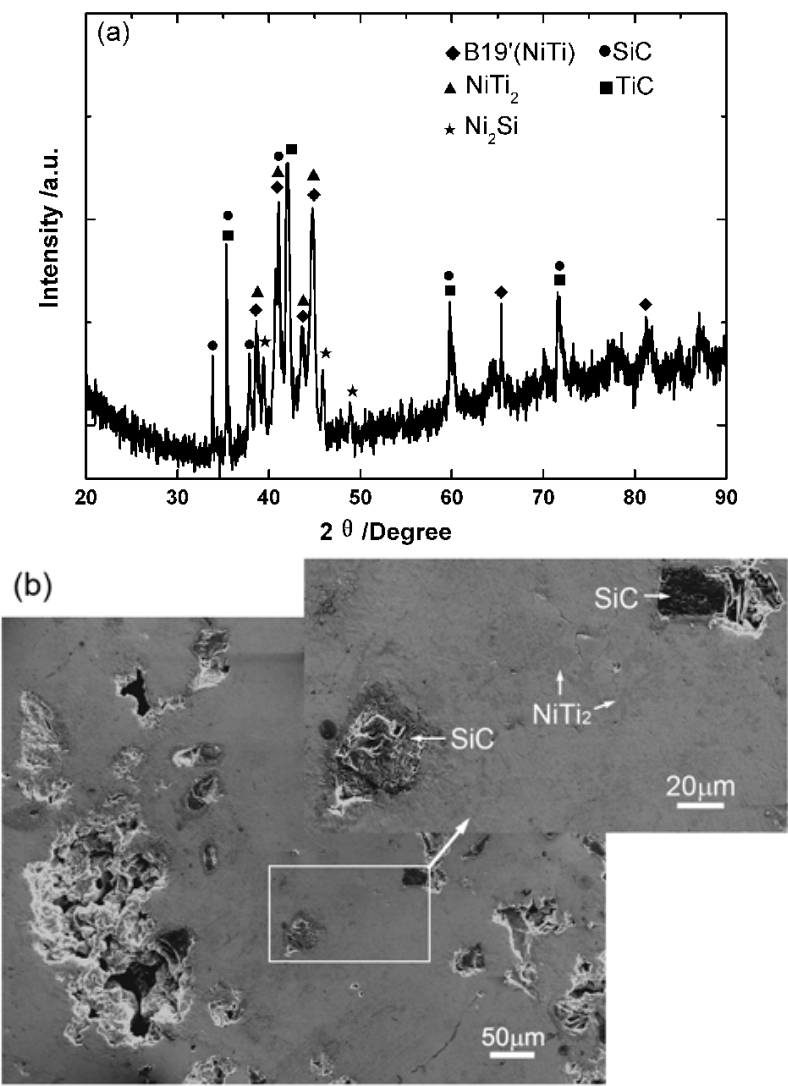

Figure 3. (a) XRD pattern reveals the phase constitution and (b) SEM image shows $\mathrm{SiC}$ particles embedded in the matrix of $12 \mathrm{wt} . \% \mathrm{SiC} / \mathrm{Ti}-43.8$ at. $\% \mathrm{Ni}$ composite.

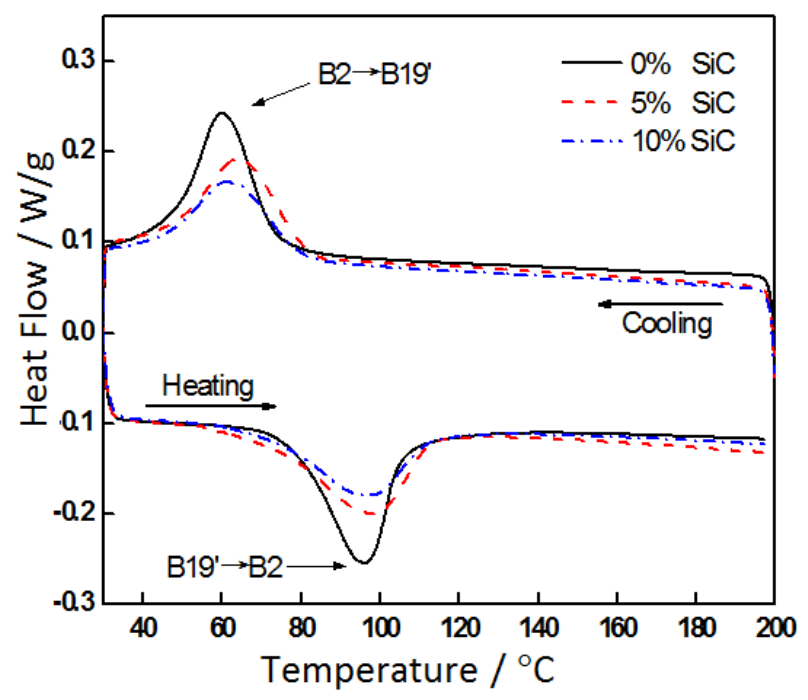

Figure 4. DSC curves of NiTi alloy based composites fabricated by adding different amounts of $\mathrm{SiC}$ particles.
To better understand the mechanism of the thermal expansion behavior of porous $\mathrm{SiC} / \mathrm{Ti}-\mathrm{Ni}$ composites and reveal the fundamental of their NTZE effect, the theoretical CTEs predicated by different classical models were compared with the experimental results in the present study. So far, there are several classical models for prediction of CTE of composites, which include the ROM law [11], Turner's model [12] and Kerner's model [13], and the mathematical presentations of these three models are listed in equations (2) to (4) as shown below:

$$
\begin{gathered}
\alpha_{c}=\alpha_{1} V_{1}+\alpha_{2} V_{2}, \\
\alpha_{c}=\frac{\alpha_{1} K_{1} V_{1}+\alpha_{2} K_{2} V_{2}}{K_{1} V_{1}+K_{2} V_{2}} \\
\alpha_{c}=\alpha_{1} V_{1}+\alpha_{2} V_{2}+\frac{V_{1} V_{2}\left(\alpha_{1}-\alpha_{2}\right)\left(K_{1}-K_{2}\right)}{V_{1} K_{1}+V_{2} K_{2}+\left(3 K_{1} K_{2} / 4 G_{2}\right)},
\end{gathered}
$$

where $\alpha, \mathrm{V}, \mathrm{K}$ and $\mathrm{G}$ are the CTE, volume fraction, bulk modulus and shear modulus of materials, and the subscripts c, 1, and 2 refer to the composite, SiC particles and $\mathrm{Ti}-\mathrm{Ni}$ matrix respectively. As for the experimental data, the weight fraction of $\mathrm{SiC}$ of the $\mathrm{SiC} / \mathrm{Ti}-\mathrm{Ni}$ composites needs to be converted into volume fraction by the following equation for further comparison to the classical models:

$$
\mathrm{V}_{1}=\frac{\mathrm{W}_{1} \rho_{2}}{\mathrm{~W}_{1} \rho_{2}+\left(1-\mathrm{W}_{1}\right) \rho_{1}}
$$

where $\mathrm{W}$ is the weight fraction and $\rho$ is the density, the subscripts 1 , and 2 refer to the $\mathrm{SiC}$ particles and $\mathrm{Ti}-\mathrm{Ni}$ matrix respectively.

All parameters used for the above calculation are given in Table 2. Since the $\mathrm{SiC}$ particles only interact with the Ti-Ni matrix rather than the pores, thus the parameters of dense Ti-43.8at.\%Ni are used in the following calculation. Density of Ti-Ni alloy is obtained via measuring the Ti-43.8at.\%Ni dense alloy via the drainage method. Moreover, as for the ideal porous material, the coefficient of thermal expansion equals to that of the dense one. Thus the CTE of porous Ti43.8at.\% $\%$ in the negative thermal expansion temperature range is used for calculation. $\mathrm{K}$ and $\mathrm{G}$ of the Ti-Ni matrix are calculated from the elastic modulus $\mathrm{E}$ and Poisson ratio of NiTi alloy with the following formulas:

$$
\mathrm{K}=\frac{\mathrm{E}}{3(1-2 v)}
$$

$$
\mathrm{G}=\frac{\mathrm{E}}{2(1+v)}
$$


Table 2. Parameters of Ti-Ni alloy and $\mathrm{SiC}$ used for the thermal expansion models calculation.

\begin{tabular}{|c|c|c|c|c|c|c|}
\hline Materials & $\begin{array}{l}\text { Density } \\
\left(\mathrm{g} \cdot \mathrm{cm}^{-1}\right)\end{array}$ & $\begin{array}{c}\text { E } \\
\text { Gpa }\end{array}$ & $\begin{array}{c}\text { K } \\
\text { Gpa }\end{array}$ & $\begin{array}{c}\text { G } \\
\text { Gpa }\end{array}$ & $\begin{array}{l}\mu \\
-\end{array}$ & $\begin{array}{c}\alpha \\
10^{-6} \mathrm{~K}^{-1}\end{array}$ \\
\hline Ti-Ni & 6.22 & $83^{[14]}$ & 81.4 & 31.2 & $0.33^{[14]}$ & -7.92 \\
\hline $\mathrm{SiC}$ & 3.21 & - & $225^{[15]}$ & $192^{[15]}$ & - & $4.45^{[16]}$ \\
\hline
\end{tabular}

The ROM law simply considers the CTE of composite as the weighted sum of the CTE of each component with neglecting all interactions between different components, which is applicable to composites of simple cases such as having multilayer-structured. The Turner model describes the thermal expansion behavior of particulate reinforced composites with consideration of the uniform hydrostatic stresses between different components. On the other hand, the Kerner model works for the composite consisting of spherical particles dispersed in the matrix, by taking both normal and shear stresses into account. In this study, only the major components of the $\mathrm{SiC} / \mathrm{Ti}-\mathrm{Ni}$ composite, i.e., $\mathrm{Ti}-\mathrm{Ni}$ matrix and $\mathrm{SiC}$ are taken into account to calculate the theoretical CTEs, regardless of the limited amount of chemical reactions between them.

In Figure 5, the as-calculated CTEs are compared with the experimental results obtained from the composites with $\mathrm{SiC}$ weight fractions of $5 \%, 10 \%$ and $12 \%$, which are of negative CTEs. It is clear that our experimental data lies closest to Tunner's model especially at low $\mathrm{SiC}$ fraction and deviates from all models with increasing $\mathrm{SiC}$ fraction. This can be explained as the factor that the irregular-shaped $\mathrm{SiC}$ particles embedded in the Ti-Ni matrix shown in Figure 3(b) as reinforcement particles introduce complicated internal stress in the matrix via the chemical reactions. Thus neither the Kerner's model for the spherical particle case nor the Turner's model only considering the normal pressure of the reinforcements can fully describe the thermal expansion behavior of the $\mathrm{SiC} / \mathrm{Ti}-\mathrm{Ni}$ system, not even the ROM rule neglecting all interactions between different components. Moreover, this intrinsic internal stress due to the constraint between the PTE SiC and the NTE porous Ti-Ni matrix plus extra internal stress caused by the thermal mismatch of the above components upon heating will finally contribute to the CTE of the whole system, and thus plays an important role in the thermal expansion behavior of the composites.

In the present work, different amounts of SiC particles of irregular shape were mixed with Titanium and Nickel powders to form SiC/Ti-Ni composite, so that the CTE of the composite is not fit the predictions of the ROM law and the Kerner model. For cases where only small amounts of $\mathrm{SiC}$ particles were used, less than $10 \%$ for example, the CTE of the composite can be well explained by the Turner model where the chemical interactions between the components is negligible, as depicted in Figrue 5. However, when relatively large amounts of $\mathrm{SiC}$ were added into the matrix, the interactions between the mixing components became significant and increasing amounts of secondary phases may present apart from the
$\mathrm{SiC}$ particles and the NiTi matrix, as discussed in the previous section. To predict the CTE of such composites with complicated and multiple components, the impact of the secondary phases must be taken into account and their effects on the overall CTE of the composite is unnegligible. The present work reports that the assintered porous NiTi alloys exhibiting NTE behavior within the temperature range of 100 to $140{ }^{\circ} \mathrm{C}$, and the range is strongly affected by $\mathrm{Ni} / \mathrm{Ti}$ ratio. Moreover, it should be noted that the thermal expansion response of shape memory alloys can be further affected by thermal and mechanical treatments, for instance, Kainuma et al. [17] investigate the effect of cold rolling deformation on the thermal expansion behavior in a $\mathrm{Cu}-\mathrm{Zn}-\mathrm{Al}$ alloy.

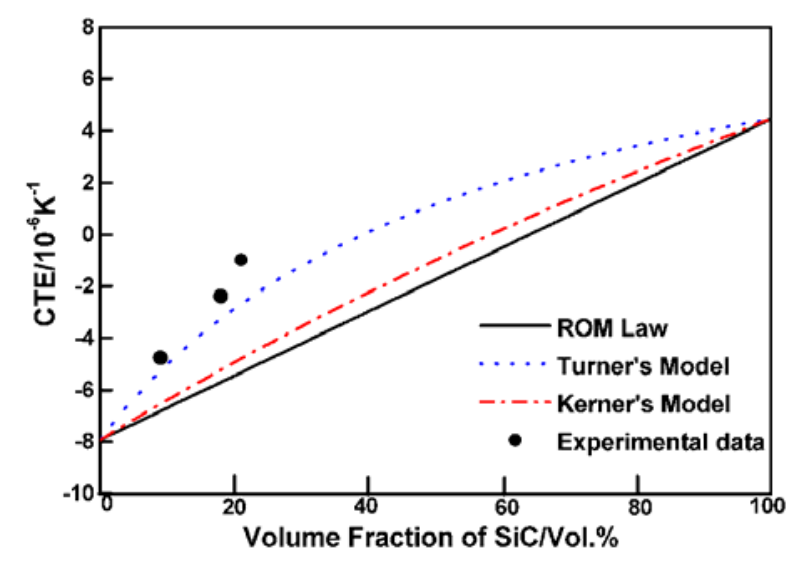

Figure 5. Comparison of experimental CTEs with theoretical predicted ones of porous $\mathrm{SiC} / \mathrm{Ti}-\mathrm{Ni}$ composites with different $\mathrm{SiC}$ weight fraction $(5 \%, 10 \%$ and $12 \%$, note: corresponding volume fractions are used in the figure).

\section{Summary}

To sum up, the porous $\mathrm{SiC} / \mathrm{Ti}-\mathrm{Ni}$ composite with optimized high temperature NZTE property have been successfully fabricated via traditional powder metallurgy by tuning the $\mathrm{Ni}$ and $\mathrm{SiC}$ fractions. The porous $12 \mathrm{wt} . \% \mathrm{SiC} / \mathrm{Ti}-43.8$ at.\%Ni composite exhibits very low coefficient of thermal expansion (CTE) of $-0.976 \times 10^{-6} \mathrm{~K}^{-}$ ${ }^{1}$ from 114.08 to $131.50{ }^{\circ} \mathrm{C}$. The NTE and NZTE effects of $\mathrm{SiC} / \mathrm{Ti}-\mathrm{Ni}$ composites are comprehensive results generated from the contraction of Ti-Ni matrix controlled by the austenite transformation, the normal expansion of $\mathrm{SiC}$ particles and thus induced internal stress upon heating in certain temperature range.

\section{Acknowledgements}

This research was supported by the National Natural Science Foundation of China under Grant Nos. 51571092 and 51401081, the Pearl River Young Scholar Program (2013J2200037) of Science and Technology Project of Guangzhou, and the Key Project of the Natural Science Foundation of Guangdong Province under grant No. S2013020012805. 


\section{References}

1. J.S.O. Evans, T.A. Mary, A.W. Sleight, Physica B. 241-243, 311 (1998)

2. D.P.H. Hasselman, Am. Ceram. Soc. Bull. 49, 1033 (1970).

3. T.A. Mary, J.S.O. Evans, T. Vogt, A.W. Sleight, Science 90, 272 (1996)

4. K. Takenaka, Sci. Technol. Adv. Mat. 13, 013001 (2012)

5. K. Otsuka, X. Ren, Prog. Mater. Sci. 50, 511 (2005)

6. H. Mavoori, S. Jin. JOM 50, 70 (1998)

7. X.W. Li, Z.Q. Zheng, J.F. Li, S.C. Li, X.Y. Wei, Rare Metal Mat. Eng. 36, 879 (2007)

8. H.J. Jiang, S.Cao, C.B. Ke, X. Ma, X.P. Zhang, Mater. Lett. 100, 74 (2013)

9. J. Uchil, K.P. Mohanchandra, K.G. Kumara, K.K. Mahesh, T.P. Murali, Physica B 270, 289 (1999)

10. J. Bhagyaraj, K.V. Ramaiah, C.N. Saikrishna, S.K. Bhaumik, Gouthama, J. Alloy. Compd. 581, 344 (2013)

11. L. Geiger, M. Jackson. Adv. Mater. Process 136, 23 (1989)

12. P.S. Turner, J. Res. Natl. Bureau. Stand. 37, 239 (1946)

13. E.H. Kerner, Proc. Phys. Soc. 69, 808 (1956)

14. Y.F. Zheng, L.C. Zhao, Biomedical nickel-titanium alloys (Chinese Science Press, Beijing, 2004)

15. W.R.L. Lambrecht, B. Segall, M. Methfessel, M. Van Schilfgaarde, Phys. Rev. B 15, 3668 (1991)

16. Z. Li, R.C. Bradt, J Mater Sci 21, 4366 (1986)

17. R. Kainuma, J.J. Wang, T. Omori, Y. Sutou, K. Ishida, Appl. Phys. Lett. 80, 4348 (2002) 